\title{
The Transformation of Teacher Authority in Schools
}

\author{
Yan Du \\ Department of Education in East China Normal University, Shanghai, 200062, China \\ dualisa@163.com
}

Keywords: teacher authority, transformation, Emile, Rousseau

\begin{abstract}
With the changes of the times, the concept of teacher authority has been given new contents.At present, the authority of teachers in China is extruding from the traditional "domination-obedience" and showing itself in the educational situation with a new attitude.The main reason for the transformation of teacher authority is that our society has shifted from "acquaintance society" to "civil society".Therefore, school teachers should rebuild teachers' authority from four aspects: improving professional ethics, applying educational wisdom, laying a solid theoretical foundation and correctly positioning their roles.
\end{abstract}

\section{Introduction}

Childhood has its place. Adults should be regarded as adults and children as children.But when we see children as children, do children see us as teachers? In reality, schools have become "service industries", parents are the "god" of teachers, and teachers gradually lose their authority.This paper will mainly discuss the causes of the gradual loss of school teacher authority, and in the current transition of teacher authority, how should our teachers do.

\section{The meaning of teacher authority}

According to the forming way of authority, the teacher authority can be divided into external sparkling authority and internal shaping authority.External sparkling authority is a form of authority derived from teachers' social status or professional image.The inner model of authority is a kind of power which is formed by the inner spirit of the teacher.

Some scholars also believe that teacher authority means that teachers exert influence on students in the way of education, so as to make students' moral, intellectual and physical development.It can either manifest as control and compliance, or as communication and negotiation.The former reflects the absoluteness of the teacher's authority, while the latter partly reflects its sharing.

At present, the authority of teachers in our country is transforming. The teacher authority is getting rid of the traditional "domination-obedience" barrier and showing itself in the educational context with a new attitude.

\section{Reasons for the transformation of teacher authority}

Nowadays, children's lying is often the main cause of conflict between teachers and parents.It is 
because children often lie to parents that the authority of teachers is constantly questioned and challenged by parents.Rousseau said, "we have to explain to children what lying is. There are two kinds of lies. One is to lie about one's future obligations. The first is to deny what he has done, or to assert that he has done something he has not done.In a word, it was he who told the truth when he knew it was not so.The second is to make promises which he does not intend to keep, and, in short, to express an intention contrary to his own."

When we teach, we often simply tell our children, "Don't lie!"But they don't tell the child exactly what a lie is.Moreover, all the promises made by children are in themselves invalid, for they have limited opinions and can only see the situation, so they cannot understand what they have promised when they make them.Children don't realize how much trouble their lies can cause teachers and parents.All they have in mind is how to get out of the present difficulty, and whatever means are available which will have no immediate effect.It is because children do not know what lies are, and the harm of lies, children will through the form of lying to help themselves out of difficulties, so that the difficulties on the teacher.Parents, by instinct, are more likely to trust their children.As a result, the sense of trust between teachers and parents is lost, how can parents be willing to give authority to teachers?

The ongoing loss of teacher authority, ostensibly caused by parents, is in fact closely related to the transformation of our society.Our society has shifted from an acquaintance society to a civil society.In the "acquaintance society", we pay attention to the relationship and order, the relationship between acquaintances is difficult to cut off, so students and parents should respect the authority of teachers.In addition, at that time, students received information through a single channel, and teachers mastered a large number of knowledge that students did not have, so teachers became the absolute authority.Their words became the treasure of the students. The traditional teacher image in China has a strong "ethical" color.However, this kind of teacher authority derived from the education system (agreed, legal), however "sacred" inviolable, it is after all outside the teacher's individual quality of the formal authority, is imposed on the students of the transcendental authority.The reason why such "external attachment" of teacher authority has a firm position is that it conforms to the needs of large area of knowledge transmission in pre-industrial society and industrial society.However, the "external dependence" of teacher authority not only causes the servility and duplicity of the students, but also makes the development of teachers in a passive and negative situation.In essence, in the "external attachment" of teacher authority, the teacher's own existence is only a part of traditional ethics and legal norms, and the teacher has no independence or self-esteem of his own, and the teacher is just a tool of authoritarianism.

In the information age, due to the development of the Internet, people have more access to information, and our educational resources are more open and diversified. All kinds of information and knowledge are filled around students, and some knowledge fields are not even known by teachers. The society has also transformed into a civil society.In such a society, the authority of teachers is inevitably affected.In civil society, education aims to cultivate not only learners of general knowledge, but also insightful and creative people who can adapt to the rapidly changing society.Our society cannot go back to the way it was before.In this social context, teacher authority has to transform.

\section{Suggestions}

At present, the teacher-student relationship is changing from rigidity, power and conservatism to equality, flexibility and creativity.If our teachers want to better adapt to the society, their teacher authority should also change from "external dependence" to "internal formation".In the modern transformation of teacher authority, teachers themselves must keep up with the requirements of the 
development of The Times and constantly improve themselves, so as to fundamentally establish their own education and teaching authority.

Firstly, teachers should enhance professional ethics.

Primary and secondary school teachers are faced with mostly underage children.The task of teachers is not only to teach knowledge, but also to help students develop good habits of behavior, so that students have good moral character.Therefore, teachers should teach by their words and deeds, first improve their professional ethics, so as to gain the respect of students, conquer students' hearts, so as to fundamentally lay the "internal authority" of teachers themselves.

Teachers should be patriotic and law-abiding, love their jobs, care for students, impart knowledge and educate students, lifelong learning.Only teachers themselves by example, students will consciously or unconsciously imitate the teacher, is the so-called "peaches and plums do not speak, groin".At present, students learning is no longer a kind of "external learning" which is free from the teacher's authority, but a kind of "spiritual learning" which comes from the heart.Therefore, improving teachers' professional ethics is the only way for teachers to rebuild their authority.

Secondly, teachers should have education wisdom.

Rousseau said in Emile "The most important part of art which teachers should master is: in view of the situation to exhort, can predict the young man under what circumstances might listen to him, under what circumstances may be so stubborn, in order to let the experience to teach him everywhere, do not make again at the same time he suffered too much danger.He must be shown his mistakes before they are made;And never blame him after he has done it, for it will only make him angry and make him rebel against you out of pride.It is no good teaching him a lesson if it arouses his antipathy.The worst thing, I thought, was to say to him: 'I told you so."In fact, what Rousseau is emphasizing is that teachers should have educational wisdom and learn to use it.

Because the teacher who has educational wisdom can always find the new problems and new situations of the students. To grasp the opportunity of education and transform the educational contradictions and conflicts,according to the actual situation of students to make decisions in time,and adjust the educational behavior.To enable students to actively participate in school life, love learning and creation can make students willing to engage in spiritual dialogue with others. When a teacher has his/her unique educational wisdom, he/she is more likely to be a good teacher.

At present, if a teacher wants to establish authority, he must constantly enrich the connotation of educational wisdom in educational practice and realize the unity of intellectual wisdom, rational wisdom, emotional wisdom and practical wisdom.Specifically, teachers should form intellectual wisdom through overall perception and intuitive grasp.Through theoretical thinking, grasp the law of understanding, the formation of rational wisdom.Use professional sense, moral sense, interpersonal communication, forming emotional wisdom. Through the accumulation of individual experience, perception of practice, teaching reflection, the formation of practical wisdom. Only the unity of these four kinds of wisdom, the teacher can better establish the "inner authority".

Thirdly, teachers should solid theoretical foundation.

A qualified teacher should be able to speak fluent mandarin, write good blackboard writing, have a good eloquence, a good set of methods, and be able to give correct guidance and help according to the students' physical and mental development.Only in this way, the teacher can guarantee the order of education and teaching activities, in order to establish their own educational authority.

Therefore, teachers should not only master the knowledge covered by the subject they teach and have perfect subject knowledge and skills, but also understand the relevant knowledge of natural science and social science.Understand the knowledge and skills of psychology, class management, modern technology and other aspects, and try your best to become an "all-round teacher".In this way, the teacher's own educational behavior is more scientific, artistic and individual. When the 
teacher's own theoretical foundation is solid, the teacher can stand on the platform, for the students convinced and respect.

Fourthly, teachers should position their role correctly.

Now that we have moved from an "acquaintance society" to a "civil society", school teachers need to redefine their role as teachers.Teaching is no longer an "authority" profession.Teachers should shape their own authority through their inner ability.

Just think: once the teacher has the lofty moral character, the outstanding ability, the wide range of knowledge and the outstanding insight, how can the student not be convinced, is it dumping, how can not "pro its teacher, the letter its way"? This kind of "internally generated" teacher authority is exactly to remove "power" to protect "power" to add "faith" to "prestige", is the teacher's reasonable influence on students and "subtle influence", this is the new era teachers should have the role of positioning.Our teachers are no longer the ones who call the shots, but the "chief among equals".Teachers should take interactive communication as the main means to win the authority, guide students to form the correct world view, outlook on life and values with a friendly attitude, and play the leading role of teachers as the "chief in equality". When teachers adapt to this new role, students' respect and trust for teachers will be the reward of students' willingness to give teachers, without any compulsion or necessity.

\section{Summary}

Rousseau's naturalism has been applied in contemporary school education.However, in the process of application, many schools have errors, resulting in the continuous loss of the authority of teachers.In the face of the continuous loss of school teacher authority, the first thing teachers need to change is themselves. Teachers should build equal, democratic and harmonious teacher-student relationship by constantly improving their own professionalism.This kind of "internally generated" teacher authority is what our current society needs.

\section{Acknowledgements}

The authors gratefully acknowledge the professor support from.

\section{References}

[1] Rousseau, translated by Li, P. O. (2015).Emile. Beijing: commercial press.

[2] Dai, X.G. (2013).Emile and Rousseau's Nature Education. Peking University education review, 1, $147-156$.

[3] Liu, X. F. (2013). How Emile "Talks About Education" or How Rousseau Talks About Education "Imaginary Students". Peking University education review, 1, 126-146.

[4] Liu, L. H., \& Zeng, S. P. (2015). Rousseau's Educational Intention. Journal of east China normal university (education science edition), 1, 11-17.

[5] Yang, K. Z. (1998). On Rousseau's View Of Children and Its Modern Significance. Educational research, 1, 73-77.

[6] Hou, H. Y., \& Han, X. F. (2017). Rousseau's Spread of Emile in China and Its Enlightenment Commemorating the 225th Anniversary of Emile.

[7] Zhao, L.P. (2009). Teacher authority in post-figurative culture, Higher education exploration, 5, $114-117$.

[8] Peng, Y. H., \& Shen, H. (2004). "Digestion" or "Reconstruction" -- reflections on teacher authority in the context of new curriculum reform. Educational science research, 06, 17-18.

[9] Li, R. H., \& Tian, Y. Y. (2018). The decline and reconstruction of university teachers' knowledge authority in the era of big data. Higher education exploration, 180 (04), 106-112.

[10] Song, Y., \& Niu, Y. F. (2016). Teacher authority: moral tension between love and punishment. Educational science research, 7, 19-25.

[11] Bao, C. Y. (2004). Clearing up and reconstructing: the Teacher Authority under the Background of New Curriculum. Journal of Hunan normal university education science, 3 (05), 32-35.

[12] Li, X. Y., \& Gu, C. L. (1999). Reflections on teacher authority. Journal of Hunan institute of education, S2, $42-43$. 
[13] Zhao, Y. Q., \& Jin, Y. L. (2003). On Culture Model and Teacher Authority \%. Research on Teacher education, 15 (006), 34-39.

[14] Zhang, Y. B. (2000). On the transformation of teacher authority in the Internet age. Education research, 09, 67-71.

[15] Zhang, L. C., \&Li, R.Z. (2003). On the modern transformation of teacher authority. Education research, 11, 70-75. 